\title{
Design and Implementation of a Novel Tool Addresses the Greatest Cause of Wrist Injuries at Bayer Healthcare
}

\author{
Allen Yagjian, M.S. \\ Bayer Healthcare, 800 Dwight Way, Berkeley CA 94577, USA
}

\begin{abstract}
Sanitary clamp wingnut manipulation is the fifth most frequent cause of injuries in the production areas of the Bayer Healthcare site in Berkeley, California. Task analysis showed that manual manipulation of clamp wingnuts had concurrent multiple risk factors, including: awkward postures, high forces, contact stresses, and high frequency. Task elimination was not an option. Several tools on the market were researched and tried but it was found that no existing tools would alleviate the associated ergonomics risk factors. An interim tool found on the market was used as a short term solution until an optimal design could be manufactured. A tool was designed, fabricated, and tested in-house at the Bayer machine shop. The tool was originally designed to fit all variations of clamp wingnuts, but then was found to fit too loosely for some. By using a comparison between inventory and cost benefit analysis it was decided to standardize the wingnuts types leaving the two most common types. A final prototype of the tool fit these two types of wingnuts. The efficient methods by which clamps were replaced and how tools were implemented in cleanroom manufacturing areas are described in this paper. This ten month project potentially eliminated all of the ergonomics risk factors associated with clamping.
\end{abstract}

Keywords: tool design, sanitary clamp, wrist injuries, tool fabrication, case studies 


\section{Problem Description/Definition}

\subsection{Company Background}

Bayer Healthcare is a worldwide company with over 410 facility locations that researches, develops, manufactures and markets products for the prevention, diagnosis, and treatment of diseases. [1]

The Bayer Healthcare facility located in Berkeley, California in the U.S. employs more than 1,500 people in a 43-acre campus. This facility is the center for the company's global biotechnology manufacturing operations which ensures the supply of millions of units of protein therapeutics each day. The primary capacity of this site is devoted to producing a recombinant Factor VIII therapy. Factor VIII is an essential blood clotting factor manufactured for the treatment of people living with hemophilia A. The plant operates 24 hours a day, 7 days a week. Drug manufacturing at the Berkeley facility has departments including Media, Fermentation, Purification, and Packaging/Warehouse.

\subsection{Problem Description}

In the pharmaceutical production facility, sanitary clamping is a task that accounts for $15 \%$ of total injuries on site and is the 5th most frequent cause of injury. Figures 1 and 2 show sanitary clamps used in the production facility. Injury statistics, a lagging indicator, warranted intervention. Cases of tendinopathy in the upper extremity such as carpal tunnel syndrome (CTS) illustrate why it is much more appropriate to use leading indicators to warrant ergonomics considerations in design. Proactive measures at Bayer Healthcare include ergonomics surveys, ergonomics hotline, and proactive ergonomics assessments.

Fig. 1. Sanitary clamp

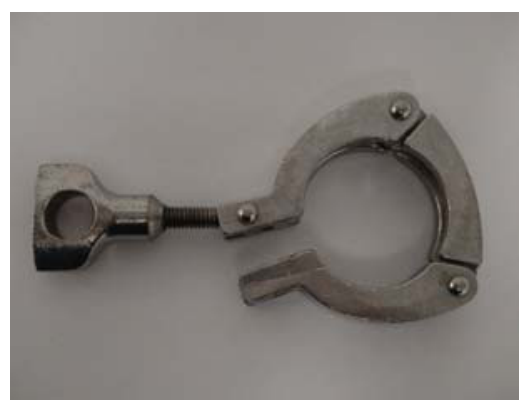

Fig. 2. Tightening a sanitary clamp

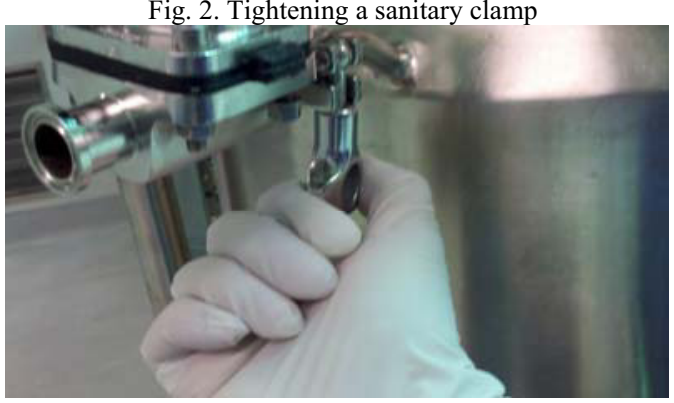

Although repetitive traumas occur over a longer period of time, tasks in a manufacturing facility are performed so often and routinely that operators still incur them. The repetitive application of forces on both tendons and muscles creates a cumulative effect that can initiate a response cycle that is extremely difficult to break. [2]

\subsection{Types of Wrist Work Related Musculoskeletal Disorders}

In the workplace, it is important to consider the factors that lead to musculoskeletal disorders (MSDs). Studies show that repetition, high forces, vibration, and posture are all factors in the development of tendinitis and CTS of the wrist. A combination of these factors shows the greatest evidence for causal relationship between the physical work factors and MSDs. [3,4] Armstrong et. al. showed that poor design of tools with respect to weight, shape, and size imposes wrist deviations and high forces on a worker's musculoskeletal system. The study also showed that holding a heavier object requires an increased power grip and high tension in the finger flexor tendons which can lead to CTS. [5]

Table 1 summarizes the postural risk factors reported in the literature for the wrist. Multiple studies number either the quantity of wrist motions, bending angle, or time associated with a high risk of developing an MSD. 
Table 1

Wrist postural risk factors reported in the literature. [6]

\begin{tabular}{lll}
\hline \multicolumn{1}{c}{ Motion } & \multicolumn{1}{c}{ Exposure: } & \multicolumn{1}{c}{ Results: Outcome and Details } \\
\hline $\begin{array}{l}\text { Wrist flexion and } \\
\text { extension }\end{array}$ & 20 to 40 hours per week & $\begin{array}{l}\text { CTS [7], increased median nerve pressure [8], } \\
\text { median nerve compression by flexor tendons [9] }\end{array}$ \\
$\begin{array}{ll}\text { Wrist ulnar deviation } \\
\text { Hand manipulations }\end{array}$ & Deviation greater than 20 degrees & Pain and pathology [10] \\
Wrist motion & $>1500$ to 2000 manipulations per hour & Tenosynovitis [11] \\
\hline
\end{tabular}

\subsection{Epidemiological and Financial Significance}

Occupational MSDs are a problem both in health and economic terms. The cost given by a conservative estimate previously published by NIOSH was $\$ 13$ billion annually. [14] In the U.S., cumulative trauma disorders account for between $56 \%$ and $65 \%$ of all occupational injuries. $[13,14]$ Overall, the estimated prevalence of upper-extremity MSDs is approximately $30 \%$. [15] The costs associated with these disorders are high - over two billion dollars of direct and indirect costs estimated annually in the US.[16] Bayer Healthcare has a Total Recordable Incidence Rate (TRIR) 60\% greater than the industry average, if reduced, could potentially save the company hundreds of thousands of dollars each year. [17] times to every situation. The following were key critical points for the tool implementation:

- Select and design a tool that can manipulate any clamp in all areas

- Provide training to operators for proper use of the tool

- Provide training for supervisors to enforce use of the tool

- Make the tool available in all areas where clamping is performed

- Stock the tool in a site warehouse for access by production personnel

- Ensure proper labeling of the tools and holders

- Setup and enforce a check-system for tool replacement

\section{Methods}

\subsection{Identifying Problem}

The incident investigation reports and ergonomics evaluations were referenced and the major risk factors were categorized as: awkward postures, high forces, contact stresses, and high frequency. These risk factors are concurrent and were shown to cause wrist pain in production technicians over time. The major factors causing these risk factors include incorrect training and the unavailability of a tool. An example is the use of renegade tools such as a screwdriver. However, it would only work for some wingnuts (ones that have a hole through them). Problems with such tools included operators using the screwdriver to tighten clamps, while others did not, thereby, making the task of opening the clamps more difficult for another operator.

To make the implementation efforts worthwhile and effective, a mandatory implementation of a tool was necessary. To achieve this, the tool needed to be readily available, functional, and applicable at all 


\subsection{Product research and testing}

Table 2

Products on the market tested for eight criteria

\begin{tabular}{|c|c|c|c|c|c|c|c|c|c|}
\hline Description & Lightweight & $\begin{array}{l}\text { Allows for } \\
\text { powergrip }\end{array}$ & $\begin{array}{c}\text { Ratcheting } \\
\text { action }\end{array}$ & Durable & $\begin{array}{c}\text { Secures to } \\
\text { wingnuts } \\
\text { well } \\
\end{array}$ & $\begin{array}{c}\text { Can be used } \\
\text { in tight } \\
\text { spaces }\end{array}$ & $\begin{array}{l}\text { Comfortable } \\
\text { grip }\end{array}$ & $\begin{array}{c}\text { Works with } \\
\text { most wing- } \\
\text { nuts }\end{array}$ & $\begin{array}{c}\text { Does not } \\
\text { require } \\
\text { adjusting }\end{array}$ \\
\hline Crescent R2 Rapid Wrench & & $\mathrm{x}$ & $\mathrm{x}$ & & & & $\mathrm{x}$ & $\mathrm{x}$ & \\
\hline $\begin{array}{l}\text { Socket Wrench with T- } \\
\text { Handle by Sieger Eng. }\end{array}$ & $\mathrm{x}$ & $\mathrm{x}$ & & & $\mathrm{x}$ & & & $\mathrm{x}$ & $\mathrm{x}$ \\
\hline $\begin{array}{l}\text { Key Wingnut Wrench for } \\
\text { clamps by Key Industrial }\end{array}$ & & $\mathrm{x}$ & & $\mathrm{x}$ & & $\mathrm{x}$ & & $\mathrm{x}$ & $\mathrm{x}$ \\
\hline Milli-Grip Adjustable wrench & $\mathrm{x}$ & $\mathrm{x}$ & & $\mathrm{x}$ & & & $\mathrm{x}$ & $\mathrm{x}$ & \\
\hline $\begin{array}{l}\text { I-Logic Torquer and } \\
\text { I-nuts }\end{array}$ & & $\mathrm{x}$ & $\mathrm{x}$ & $\mathrm{x}$ & & $\mathrm{x}$ & & & $\mathrm{x}$ \\
\hline $\begin{array}{l}\text { Wingnut Tightening Tool by } \\
\text { Berlin Food Company }\end{array}$ & $\mathrm{x}$ & $\mathrm{x}$ & & $\mathrm{x}$ & $\mathrm{x}$ & & & & $\mathrm{x}$ \\
\hline $\begin{array}{l}\text { Wingnut Tightening tool by } \\
\text { Swagelok }\end{array}$ & $\mathrm{x}$ & & & $\mathrm{x}$ & $\mathrm{x}$ & $\mathrm{x}$ & $\mathrm{x}$ & $\mathrm{x}$ & $\mathrm{x}$ \\
\hline
\end{tabular}

Since the project goal was to implement a tool that would be mandatory and standard across the site and have it available for production, this tool would have to work for every application in all production areas. It was seen that a custom tool would be the best choice because it was so important that the tool fit all applications in production and significantly reduced the ergonomics risk factors associated with clamp manipulation.

From the research and comparison of applicable tools in the market in production, one tool stood out as the best interim solution to use while a custom tool could be developed and implemented. This was the Wingnut Tightening Tool by Swagelok shown in figure 3. It was a lightweight plastic part that fit most the wingnuts and was small enough to fit in most spaces.

Fig. 3. Using Wingnut Tightening tool by Swagelok

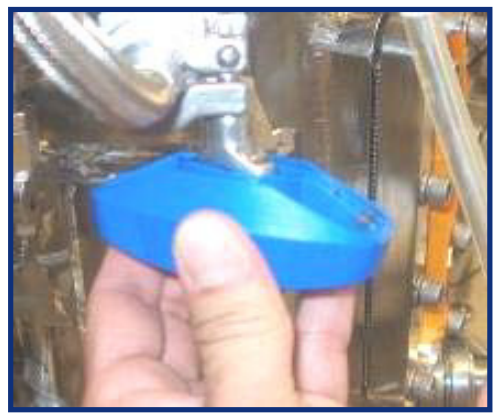

The variety of wingnuts posed a challenge in finding a tool on the market that would articulate to all the different types in the production areas across site. There were nine different clamp wingnuts types on site. Samples of all the different clamp wingnut variations were collected from production areas. An inventory sheet was developed for production personnel to fill out that would tally up the different clamp wingnuts used in each room in production areas.

The criteria given to the fabricators were based on the nine wingnut samples collected. The given criteria were to make a ratchet tool that would articulate to all nine of the wingnut samples. The required criteria were: does not slip off the nut when used, durable, lightweight, require no adjustments, no pressure points on the hand, allows for a powergrip, and ability of the tool to be used in tight spaces.

The fabricator milled a stainless steel part, shown in figure 4 , which would fit onto a $3 / 8$ " drive ratchet wrench to fit all the different wingnuts. A straight or knuckled socket extension could allow it to be used in tight spaces. The fully assembled prototype is shown in figure 6. 
Fig. 4 \& 5. Fabricated socket

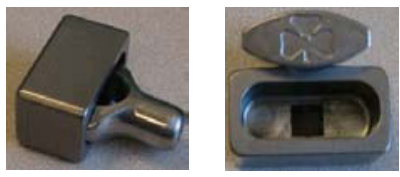

Fig. 6. Entire prototype with milled socket on a wrench

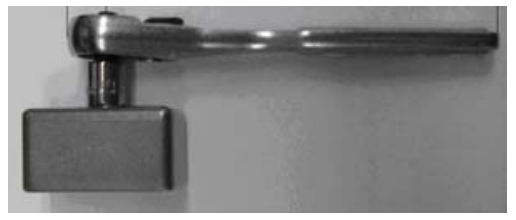

Copies of the prototype were fabricated and tested for design flaws, ease of use, and product and user safety in all areas of production. One prototype tool was given to a supervisor in each area to for the operators' evaluation based on the following criteria: functional issues, ability of the tool to be applied to all clamp manipulation in their area, and causes of product or user safety issues. They were also asked for any design recommendations that would improve the functionality of the prototype.

The prototype testing was completed after a month and the results were compiled and relayed to the fabricators. The tool did not have any significant flaws, difficulty in usage, or cause any product or user safety issues. However, multiple areas of production reported two problems: the bulky square milled socket would strike adjacent surfaces while manipulating clamp wingnuts and it fit some clamp wingnuts too loosely and would slip off when used. The variation in wingnuts in production areas was due to years of ordering from different vendors and clamp manufacturers coming out with different generations of the clamps.

The logical path forward was to replace larger and outlier clamp wingnuts in all production areas so that the dimensions of the milled steel piece on the prototype could be tightened. The tradeoff was between the cost of replacing clamps and ease of tool use (better overall articulation between clamps and the milled socket). Therefore, to accommodate the ease of use without breaking the bank, a cost analysis was performed to show management the different options and propose an optimal solution. To decide how many clamp wingnut types in production areas that the milled socket dimensions would accommodate required more information gathering.

A training and supplemental clamp wingnut inventory sheet was given to supervisors in production to fill out and return. The clamp vendors supplied quotes for both new clamps with wingnuts and just clamp wingnuts (to replace only the wingnuts). For smaller (less than 2" diameter) clamps, it was cheaper to replace the entire clamp, while for all others it would be more economical to just replace the wingnuts. A trusted clamp vendor was consulted as a subject matter expert to provide feedback and advice on the clamp replacement and tool development.

Two of the nine wingnuts in production comprised 57 percent of the total clamps. These two wingnuts were very similar in shape and size, therefore, the selling point to management was the most optimal decision was quite obvious after viewing figure 7 . The wingnuts shown in figure 8 correspond with the wingnut numbers types in figure 7 . All but wingnut types 1 and 5 were crossed out to show that they should be replaced.

Fig. 7. Frequency of wingnut types

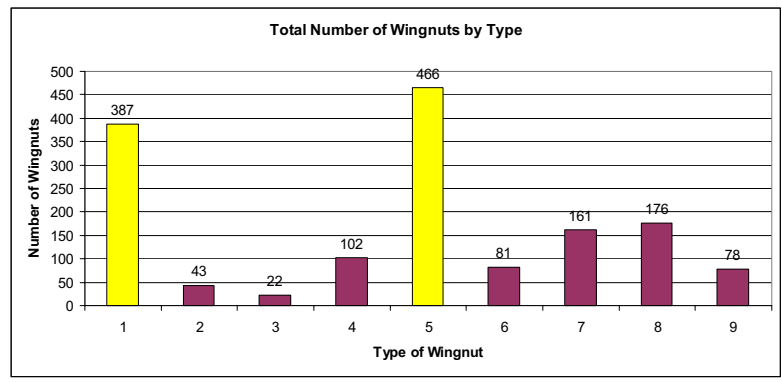

Fig. 8. Types of wingnuts ( $1 \& 5$ selected for standardization)

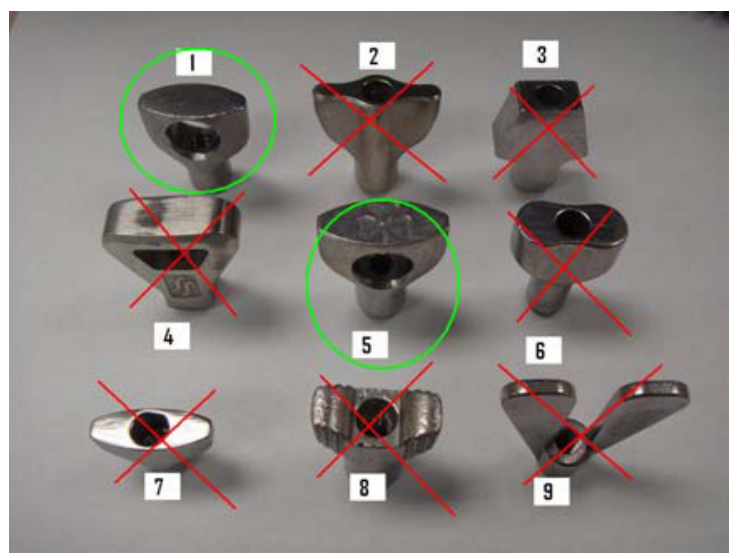

This information was given to the fabricators for development of the next prototype of the tool. The milled part is shown in figures 9 and 10. The outer edges were milled down to an oval shape to allow for better maneuvering and to provide a better fit into tight spaces. The Bayer manufacturing shop on site was requested to create a handful of the second generation tools to test in production. The same criteria used for the first prototype were used. This time there were no issues. 
Fig. $9 \& 10$. Fabricated socket second prototype
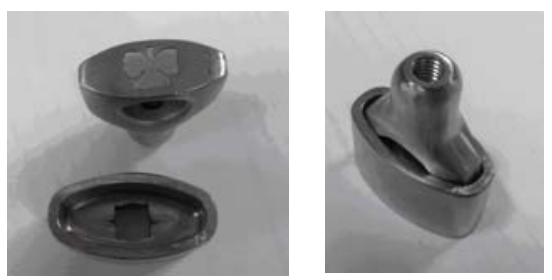

The final design was sent to a local manufacturer to do the work for the milled heads. We found a vendor for the $3 / 8$ " ratchet wrench handle we chose and had the local manufacturer put the two parts together and provide a quote for the entire tool. The entire tool was inventoried at the site warehouse.

A toolboard was designed to fit the tools and was installed 48 inches above the floor to accommodate the horizontal reach of the fifth percentile Asian female height.[18] A total of 37 toolboards were made and placed in areas where clamping was performed. The toolboard is shown in figure 11 .

Over 2000 clamp wingnuts were replaced on site in a month by the production personnel trained to gradually replace them. Bins with a placard of wingnuts to replace were placed in areas and cycled by providing new clamps as the old ones were taken out weekly for two months. After completion of the clamp nut replacements, 105 Bayer custom clamping tools were ordered for the site and placed in toolboards across site.

In order to keep the tool in its location the tool has been added as an item in monthly inspections. Also, the tool is properly labeled either by etching, colored cable tie around the neck, or colored tape. For effective housekeeping, at end of shifts, operators are required to clean up a particular room. A posted picture shows them what the area is supposed look like after the cleanup.

Figure 11. Toolboard and tools placed in an area that uses clamps

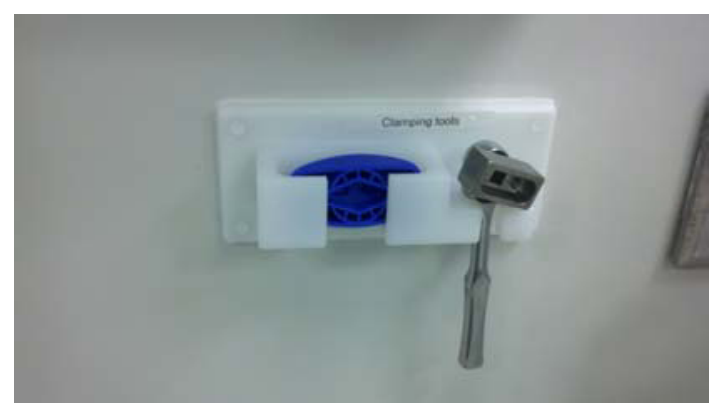

\section{Custom clamping tool effectiveness study}

A task was chosen to test the new design. During the disassembly and assembly of a cell separation skid 20 sanitary clamps wingnut were loosened and tightened. The objective was to find out if there was a difference in forces required to turn the clamp nut with and without the Bayer custom designed tool. The hypothesis was that the tool would reduce the required force.

A Chatillon force gauge was used to test the forces when tightening the clamps with and without the Bayer custom clamping tool. The nut was turned until it had any measureable resistance on the force gauge and force data was collected every 45 degrees angle turned thereafter. The moment arm for the sanitary clamp wingnut is perpendicular to the outer edge of the length of the wingnut. The same method force measurement was done again using the Bayer custom clamping tool. The force measurement required to turn the wrench was taken at the middle of the handle portion of the wrench (3.5 inches from the socket joint).

The forces required to turn the nut of the Swagelok clamp by hand and using the designed wrench are shown in figure 12 .

Fig. 12. Swagelok clamping force vs. angle turned

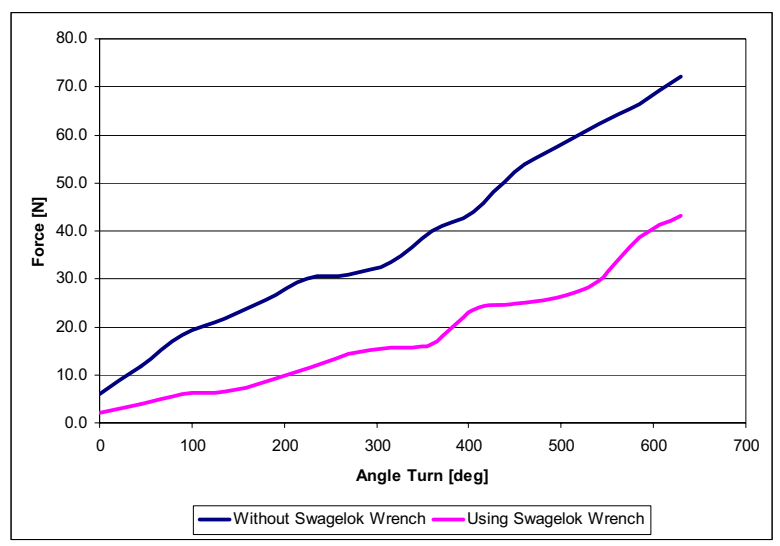

The average angle rotated when tightening the clamps was observed using video analysis. The average turning was 540 degrees with a standard deviation of 38 degrees. At 540 degrees of rotation the force on the fingers was observed to be $62.1 \mathrm{~N}$. When the wrench is used this force is reduced to $29.4 \mathrm{~N}$, resulting in a force reduction of $47 \%$. 


\section{Conclusion}

The custom designed clamping tool is effective at reducing three major ergonomics risk factors including: high force, eliminating pinch grip (now power grip), and awkward postures (if properly trained on how to use tool). This project was worthwhile because of the high number of injuries related to clamping and this tool should reduce these numbers of injuries.

This tool would be a great asset to the following industries (including but not limited to): food processing, wine making, pharmaceuticals, breweries, and distilleries.

\section{References}

[1] Bayer Healthcare: Science For a Better Life. January 2009. $<$ http://www.bayer.com/en/bayer-healthcare.aspx $>$

[2] Marras, W. S.. Basic Biomechanics and Workstation Design. Handbook of Human Factors and Ergonomics. John Wiley \& Sons, Inc.. Hoboken, NJ. (2006)

[3] Putz-Anderson, V.. Cumulative Trauma Disorders: A Manual for Musculoskeletal Diseases of the Upper Limbs. Taylor \& Francis, London. (1993)

[4] Bernard, B. P.. Musculoskeletal Disorders and Workplace Factors.. U.S. Department of Heath and Human Services(DHHS), Public Health Service, Centers for Disease Control and Prevention, National Institute for Occupational Safety and Health (NIOSH). Washington, DC. p.97-141. (1997)

[5] Armstrong, T. J., Buckle P., Fine L.J., Hagberg M., Jonsson B., Kilbom A., Kuorinka I.A., Silverstein B.A., Sjogaard G., Viikari-Juntura E.R.. A Conceptual Model for Work-Related Neck and Upper-Limb Musculoskeletal Disorders. Scandinavian Journal of Work, Environment and Health. 9:73-84. (1993)

[6] Kuorinka I., Forcier L.. Work-Related Musculoskeletal Disorders (WMSDs): A Reference Book for Prevention. Taylor and Francis Inc. (1995)

[7] De Krom M, Kester A.D.M., Knipschild P.G., Spaans F.. Risk Factors for Carpal Tunnel Syndrome. American Journal of Epidemiology. 132(6): 1102-1110. (1990)

[8] Smith E. M., Sonstegard D.A., Anderson W. H. Jr.. Carpal Tunnel Syndrome: Contribution of Flexor Tendons. Arch Phys Med Rehabil. 58(9): 379-85. (1977)

[9] Armstrong T. J., Chaffin D.B.. An Investigation of the Relationship Between Displacements of the Finger and Wrist Joints and the Extrinsic Finger Flexor Tendons. J Biomech. 11(3):119-28. (1978)

[10] Hunting W., Laubli T., Grandjean E.. Postural and Visual Loads at VDT Workplaces. Ergonomics. 24(12):917-31. (1981)

[11] Hammer A. Tenosynovitis. Med Rec. p.353-355. (1934)

[12] Schoenmarklin RW, Marras WS. Industrial Wrist Motions and Incidence of Hand/Wrist Cumulative Trauma Disorders. Ergonomics. 37(9): 1449-59. (1993)
[13] Melhorn J. M.. Cumulative trauma disorders and repetitive strain injuries. Clinical Orthopaedics and Related Research. 351:107-126. (1998)

[14] Pilligan G., Herbert R., Hearns M., Dropkin J., Landsbergis P., Cherniack M.. Evaluation and management of chronic workrelated musculoskeletal disorders of the distal upper extremity. American Journal of Industrial Medicine. 37:75-93. (2000)

[15] Yassi A.. Repetitive strain injuries. Lancet. 349:943-947. (1997)

[16] Verhagen A. P., Bierma-Zeinstra S.M., Feleus A., Karels C., Dahaghin S., Burdorf L., de Vet H.C., Koes B.W.. Ergonomic and physiotherapeutic interventions for treating work-related complaints of the arm, neck or shoulder in adults. Cochrane Database of Systematic Reviews. 3:1-34. (2006).

[17] US Department of Labor. Injuries, Illnesses, and Fatalities. OSHA recordable case rates 2007 incidence rates, by industry, for nonfatal work-related injuries and illnesses. October 2008. http://www.bls.gov/iif/oshsum.htm

[18] SEMI S8-1103 C 1995, 2003. Safety Guidelines for Ergonomics Engineering of Semiconductor Manufacturing Equipment. 